\title{
Chemosensitizing effect of shRNA-mediated ERCC1 silencing on a Xuanwei lung adenocarcinoma cell line and its clinical significance
}

WEIWEI WANG ${ }^{1,2^{*}}$, LIJUN ZHANG $^{3,4^{*}}$, LIANG LIU $^{5}$, YONGFA ZHENG $^{6}$, YONG ZHANG ${ }^{1,2}$, SIYUAN YANG ${ }^{2,7}$, RONGLIANG SHI $^{8.9}$ and SHAOJIA WANG ${ }^{2,10}$

${ }^{1}$ Department of Chest Surgery, The Third Affiliated Hospital of Kunming Medical University

(Tumor Hospital of Yunnan Province); ${ }^{2}$ Department of Oncology, Kunming Medical University, Kunming, Yunnan 650031; ${ }^{3}$ Department of General Surgery, Ganmei Affiliated Hospital of Kunming Medical University (The First People's Hospital of Kunming); ${ }^{4}$ Department of Surgery, Kunming Medical University, Kunming, Yunnan 650032; ${ }^{5}$ Department of Oncology, Shanghai Medical College, Fudan University, Shanghai 200032; ${ }^{6}$ Department of Oncology, Renming Hospital of Wuhan University, Wuhan, Hubei 430060; ${ }^{7}$ Department of Breast

Surgery, The Third Affiliated Hospital of Kunming Medical University (Tumor Hospital of Yunnan Province),

Kunming, Yunnan 650031; ${ }^{8}$ Department of General Surgery, Minhang Hospital, Fudan University, Shanghai 201199; ${ }^{9}$ Department of Head and Neck Surgery, Fudan University Shanghai Cancer Center, Shanghai 200032; ${ }^{10}$ Department of Gynecological Oncology, The Third Affiliated Hospital of Kunming Medical University (Tumor Hospital of Yunnan Province), Kunming, Yunnan 650031, P.R. China

Received September 7, 2016; Accepted February 2, 2017

DOI: $10.3892 /$ or.2017.5443

\begin{abstract}
Lung cancer is a common fatal malignancy in both men and women. Xuanwei, Yunnan has the highest incidence of lung cancer in China. The area has a specific risk factor in the domestic combustion of bituminous coal, and lung cancer patients from this area tend to be resistant to platinum-based treatments. However, little is known about the mechanism of platinum resistance in patients from Xuanwei. Herein, we used lentiviral infection with shRNA to silence expression of the DNA repair enzyme ERCC1 in XWLC05 both in its RNA and protein expression level, a lung adenoma cell line derived from a patient from Xuanwei. ERCC1 expression in this cell line is high and contributes to its resistance to cisplatin. Suppression of ERCC1 decreased XWLC05 proliferation in vitro $\left(\mathrm{IC}_{50}\right.$ of cisplatin $1.34 \mu \mathrm{M}$ for shRNA-infected cells vs. $4.54 \mu \mathrm{M}$ for
\end{abstract}

Correspondence to: Dr Shaojia Wang, Department of Gynecological Oncology, The Third Affiliated Hospital of Kunming Medical University (Tumor Hospital of Yunnan Province), Kunming, Yunnan 650031, P.R. China

E-mail: wangsjkunming@163.com

Dr Rongliang Shi, Department of General Surgery, Minhang Hospital, Fudan University, Shanghai 201199, P.R. China

E-mail: docshawn@163.com

*Contributed equally

Key words: cisplatin, ERCC1, lung adenoma, XWLC05, Xuanwei patients control cells) and increased the apoptotic rate after treatment with cisplatin $(81.2 \%$ shRNA cells vs. $58 \%$ control cells, $\mathrm{P}<0.05)$. Progression-free survival was longer in ERCC1negative lung adenoma patients than those with high ERCC1 levels (30 vs. 11 months, $\mathrm{P}<0.0001$ ). ERCC1 expression was identified as a prognostic marker for overall survival in the patient cohort with operable lesions. Taken together, our data identify ERCC1 as a disease marker in lung adenoma patients from Xuanwei and confirm the significance of resection for the subsequent effect of platinum treatment in these patients. Additional studies are needed to determine the mechanism of ERCC1-induced platinum resistance in lung adenoma patients from Xuanwei.

\section{Introduction}

Lung cancer is a common malignancy in China. In 2015, the incidence was approximately 733 per 100,000 people and the age-standardized mortality rate was approximately 610 per 100,000 . Lung cancer is one of the top five most diagnosed cancers in both genders, and there is a significant upward trend in the age-standardized incidence rates in females (1). Xuanwei, Yunnan is well known for its high incidence of lung cancer (2). Domestic combustion of bituminous coal (referred to as 'smoky' coal) is the most important risk factor for lung cancer, rather than tobacco exposure (3). The highest incidence of lung cancer in Xuanwei occurs among farmers, and the most common histological type is adenocarcinoma. Women living in this area are also more susceptible to lung cancer (4-6). Therefore, lung adenoma patients in Xuanwei appear to differ from those in other areas. 
Platinum-based chemotherapy has been standard treatment for lung cancer for decades. However, the efficacy of platinum therapies can be seriously hindered by drug resistance, especially to cisplatin $(7,8)$. Cisplatin binds to DNA to create platinumDNA adducts that can induce covalent cross-linking between DNA strands. In turn, this activates the apoptotic pathway, resulting in cell death (9). Mismatch repair and nucleotide excision repair (NER) are particularly important mechanisms in the effects of platinum-based agents. NER is a highly conserved DNA repair pathway that acts by altering the helical structure of the DNA molecule and excising damaged DNA fragments. This pathway involves three important steps: recognition of DNA damage, formation of a complex that unwinds and excises the damaged portion, and finally, resynthesis of the damaged sequence and ligation (10). The excision repair crosscomplementation group 1 (ERCC1) enzyme, which recognizes and removes cisplatin-induced DNA adducts (11-13), plays a rate-limiting role in the NER pathway. High ERCC1 expression in solid tumors predicts poor prognosis and suggests a higher possibility of resistance to platinum treatments (14-20). This is also true for lung cancer patients, and low ERCC1 expression is beneficial in non-small cell lung cancer patients $(8,21-24)$.

In our previous study (25), we showed that ERCC1 expression is significantly higher in Xuanwei lung adenocarcinoma patients before treatment than patients from other areas. However, it is not known how the high ERCC1 levels affect the prognosis of this patient population. Herein, we hypothesize that high ERCC1 expression may be related to the response to platinum-based chemotherapy and may predict poor prognosis in lung adenoma patients from Xuanwei.

\section{Materials and methods}

Cell lines and cell culture. The established human lung adenocarcinoma cell line XWLC05 was obtained from No. 1 Affiliated Hospital of Kunming Medical University. Cells were maintained in RPMI-1640 medium (HyClone, Thermo Scientific, Waltham, MA, USA) supplemented with $10 \%$ fetal bovine serum (Gibco Life Technologies, Carlsbad, CA, USA), $100 \mathrm{U} / \mathrm{ml}$ penicillin (Biowest, Nuaillé, France), and $100 \mathrm{U} / \mathrm{ml}$ streptomycin (Biowest) and incubated at $37^{\circ} \mathrm{C}$ in a humidified $5 \% \mathrm{CO}_{2}$ atmosphere.

Viral infection. A lentiviral vector carrying ERCC1 shRNA was designed and constructed by GeneChem Co., Ltd. (Shanghai, China). Cells were infected with the lentivirus twice for 2 days each and positive clones were selected with puromycin $(200 \mathrm{ng} / \mathrm{ml})$ for 7-10 days. Control cell lines were generated by infecting with viruses containing the empty vector, following the same protocol.

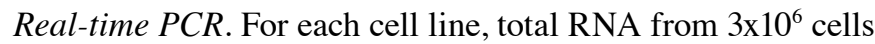
was isolated using TRIzol reagent (Invitrogen, Carlsbad, CA, USA). RNAs were then reverse transcribed into cDNAs for Real-time PCR analysis using an ExScript RT-PCR kit (Takara, Shiga, Japan). Oligonucleotide primers for ERCC1 were 5'-CGTGCTGTACCTCTCGC-3' (forward primer) and 5'-CTGAGGAACGGTTCCTG-3' (reverse primer), and primers for glyceraldehyde 3-phosphate dehydrogenase (GAPDH) were 5'-GGCCTCCAAGGAGTAAGACC-3' (forward primer) and 5'-CAAGGGGTCTACATGGCAAC-3' (reverse primer). Amplification and detection were carried out in the Applied Biosystems Prism 7900 system (Applied Biosystems, Foster City, CA, USA) using an ExScript SYBR Green QPCR kit (Takara) and the following conditions: $95^{\circ} \mathrm{C}$ for $10 \mathrm{sec}$; 40 cycles of $95^{\circ} \mathrm{C}$ for $5 \mathrm{sec}, 62^{\circ} \mathrm{C}$ for $31 \mathrm{sec}$; followed by a 30 -min melting curve analysis to verify the primer dimers. Statistical analysis was performed using the $2^{-\Delta \Delta \mathrm{CT}}$ relative quantification method.

CCK- 8 proliferation assay. Cell proliferation was measured using a CCK-8 assay kit (Dojindo, Japan) according to the manufacturer's protocol. Cells were seeded in 96-well plates ( $2 \times 10^{3}$ cells/well) and $10 \mu \mathrm{l}$ CCK- 8 solution was added to each well on days $0,1,2,3,4$, and 5 . The plates were incubated at $37^{\circ} \mathrm{C}$ in $5 \% \mathrm{CO}_{2}$ for $1 \mathrm{~h}$, and the absorbance of each sample at $450 \mathrm{~nm}$ was measured using a microplate reader. Three independent experiments were required for this assay.

Colony-forming assay. A total of 500 cells were seeded at single-cell density in 6-well plates with fresh medium with or without cisplatin and allowed to grow for at least a week. Colonies with more than 50 cells were then stained with gentian violet (Solarbio) and counted.

Western blot analysis. Western blot analysis was performed to determine protein expression levels. The cells were harvested, washed with cold phosphate-buffered saline (PBS), lysed with RIPA lysis buffer (Beyotime) for $30 \mathrm{~min}$ on ice, and then centrifuged at $12,000 \times \mathrm{g}$ for $15 \mathrm{~min}$ at $4^{\circ} \mathrm{C}$. The total protein concentration in the supernatant was determined using a BCA protein assay kit (Beyotime). Equal amounts (30 $\mu \mathrm{g}$ per lane) of protein were separated by SDS-PAGE and transferred to polyvinylidene fluoride membranes (Millipore). The membranes were blocked with $10 \%$ non-fat milk, incubated with primary antibodies, and then incubated with secondary antibodies conjugated to horseradish peroxidase. The protein bands were revealed by incubation with chemiluminescent reagents (Millipore). Antibodies to ERCC1 were from Proteintech. The antibody to $\beta$-actin was purchased from Sigma-Aldrich (St. Louis, MO, USA). Three independent protein samples were harvested and tested to make sure that ERCC1 gene has been successfully silenced.

Drugs. Cisplatin was purchased from Sigma-Aldrich and stored at a concentration of $5 \mathrm{mM}$ in dimethyl sulfoxide (DMSO). XWLC05 cells were incubated with cisplatin at a concentration of $1 \mu \mathrm{M}$ unless otherwise specified.

Cell apoptosis assay. Cells were incubated with various concentrations of cisplatin or DMSO for $48 \mathrm{~h}$ and then harvested, washed twice with cold PBS, and resuspended in $200 \mu \mathrm{l}$ binding buffer at a density of $1 \times 10^{5}$ cells $/ \mathrm{ml}$. The cells were stained with $5 \mu \mathrm{l}$ Annexin $\mathrm{V}$ and propidium iodide (PI) (BD Biosciences) for $15 \mathrm{~min}$ in the dark at room temperature and then analyzed by flow cytometry (Cytomics FC 500 MPL, Beckman Coulter). Early- and late-stage apoptosis was determined by the percentage of Annexin $\mathrm{V}^{+} / \mathrm{PI}^{-}$and Annexin $\mathrm{V}^{+} / \mathrm{PI}^{+}$ cells, respectively. The results are expressed as the mean values from three independent determinations. 
A

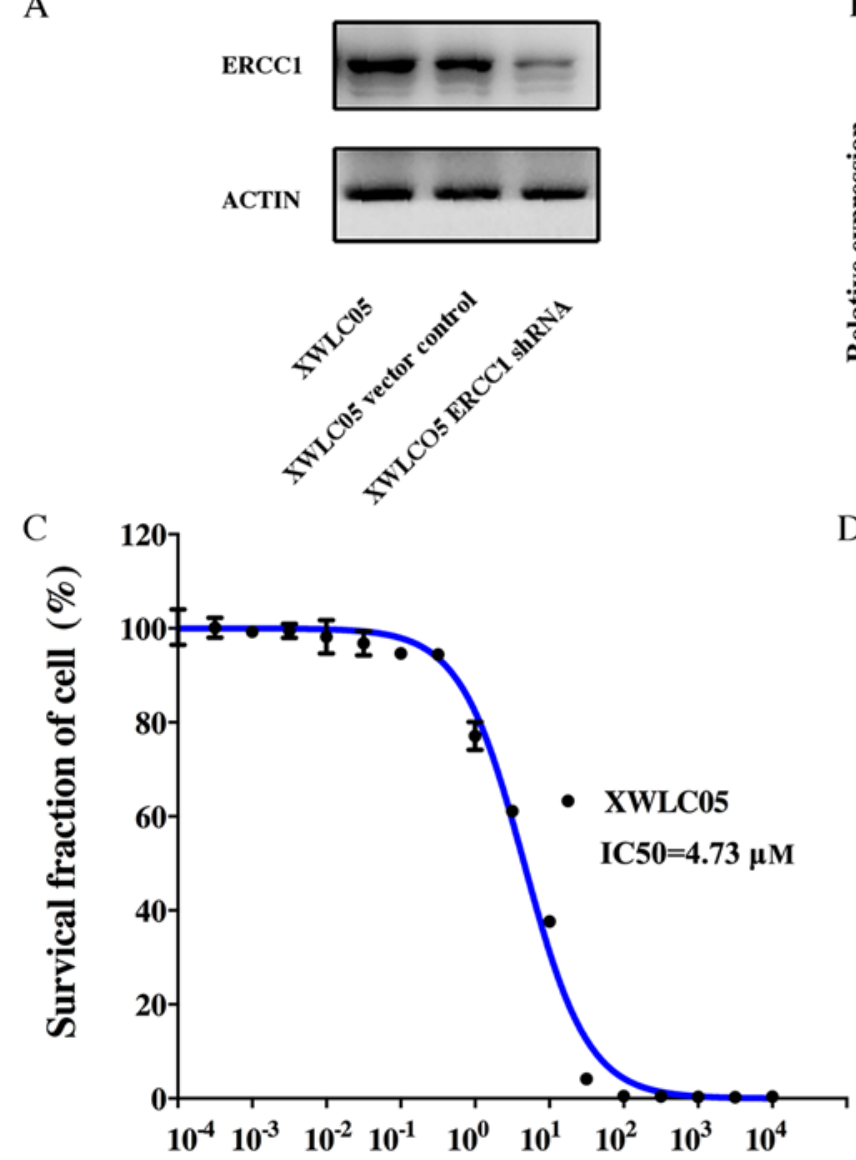

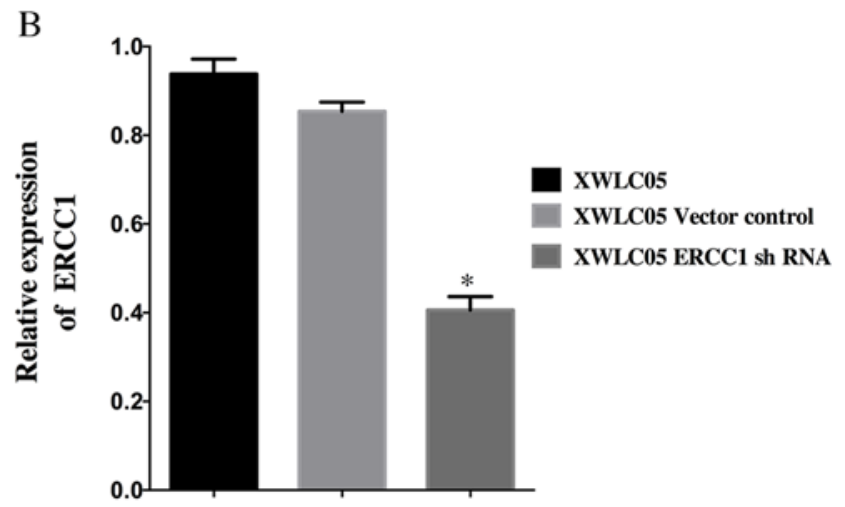

D

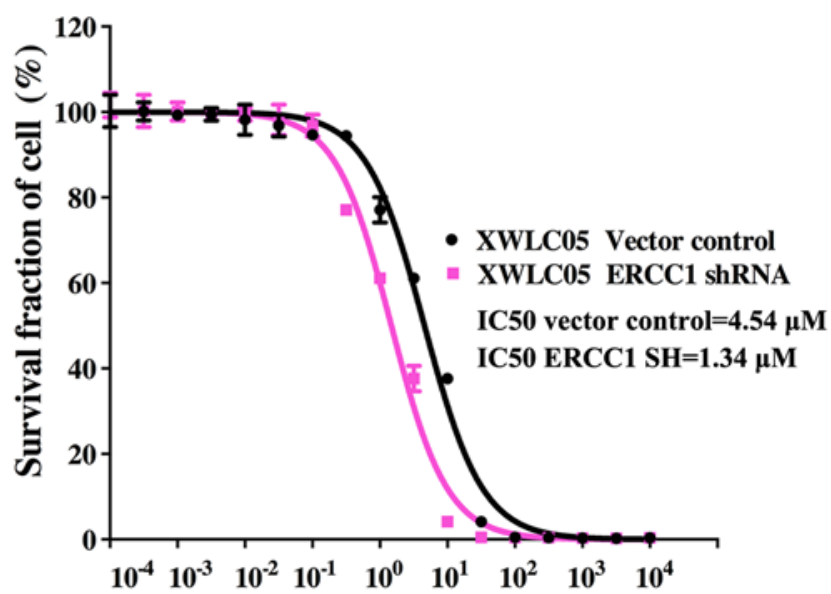

Figure 1. Cisplatin $\mathrm{IC}_{50}$ of ERCC1 silencing XWLC05 cell line decreased significantly. (A and B) Efficiently ERCC1 silencing XWLC05 cell line and its control were verified by immunoblotting and real-time PCR. (C) Cisplatin $\mathrm{IC}_{50}$ of XWLC05 was $4.73 \mu \mathrm{M}$. (D) Cisplatin IC ${ }_{50}$ of XWLC05 ERCC1-shRNA cell line and its control were 4.54 and $1.34 \mu \mathrm{M}$, respectively.

Animal experiments. The animal experiments were approved by the Institutional Animal Care and Use Committee of Kunming Medical University and were performed following Institutional guidelines and protocols. XWL05 cells stably expressing ERCC1 shRNA were generated by retroviral infection. Tumors were induced by injecting $5 \times 10^{6}$ cells of each cell line subcutaneously into 4- to 6-week-old BALB/c female athymic nude mice (Department of Laboratory Animals, Kunming Medical University). Each cell type was injected into seven mice, respectively. Mice were treated with $5 \mathrm{mg} / \mathrm{kg}$ cisplatin by intraperitoneal injection every 3 days for 2 weeks (five injections) starting immediately after injection of tumor cells. Control mice received injections of PBS. One week after the last cisplatin injection, the mice were sacrificed and the tumors were weighed. The longest diameter ' $a$ ' and the shortest diameter ' $b$ ' of the tumors were measured and the tumor volumes were calculated using the following formula: volume (in $\mathrm{mm}^{3}$ ) $=\mathrm{a} \mathrm{x} \mathrm{b}^{2} \times 0.52$, where 0.52 is a constant to calculate the volume of an ellipsoid. Three tumors per cell line were excised, fixed in $10 \%$ formalin overnight, and subjected to routine histological examination by investigators who were blinded to the tumor status. Animal experiments were repeated twice.

Immunohistochemical staining. Samples from the mouse tumor xenografts and lung tumor tissue from patients were subjected to immunohistochemical (IHC) staining to detect
ERCC1 expression. Antibodies to ERCC1 were from Maixin (Fuzhou, China, mouse clone 8F1). Paraffin-embedded sections were pre-treated and stained with antibodies as previously reported (26). Secondary antibodies against mouse or rabbit IgG were supplied in an IHC kit (\#CW2069) from Beijing Cowin Bioscience Co. Ltd (Beijing, China).

IHC scoring. Differentiated degree of these tissue samples collected from our patients were classified into well differentiated or poor differentiated according to the pathological evaluation system of our hospital. The stained tissue sections were scored separately by two pathologists blinded to the clinical parameters. The staining intensity was scored as 0 (negative), 1 (weak), 2 (medium), or 3 (strong). The staining extent was scored as the percentage of positively stained area compared with the entire carcinoma area and was scored as 0 (<5\%), 1 (5-25\%), 2 (26-50\%), 3 (51-75\%), and 4 (>75\%). Scores for the staining intensity and extent were multiplied to generate an immunoreactivity score for each sample. Tissues with a total immunoreactivity score of $<4,4,6$, and $\geq 8$ were expressed as,,-+++ , and +++ , respectively. In our research, IHC score $\geq 6$ was defined as high ERCC1 expression and IHC score $\leq 4$ was low expression.

Patient information. Sections of lung adenoma tissue were obtained from 106 operable patients who were staged based 
A

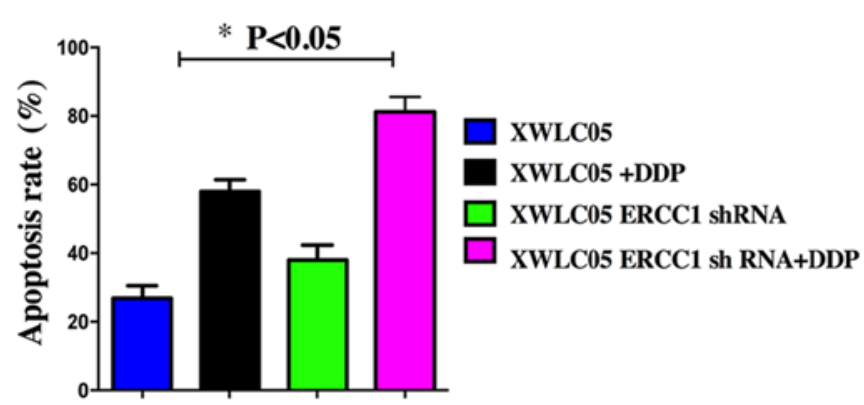

C
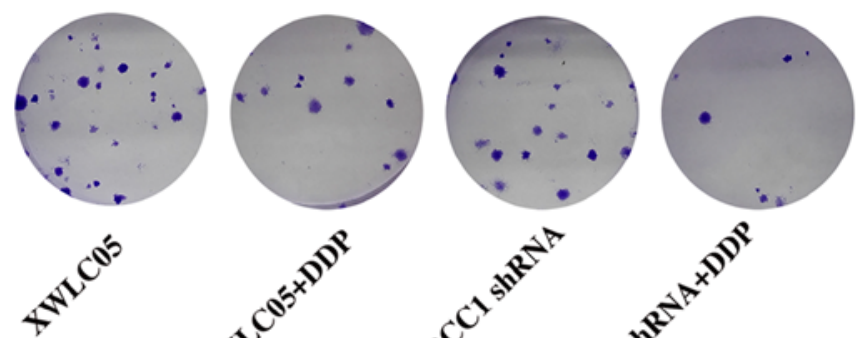
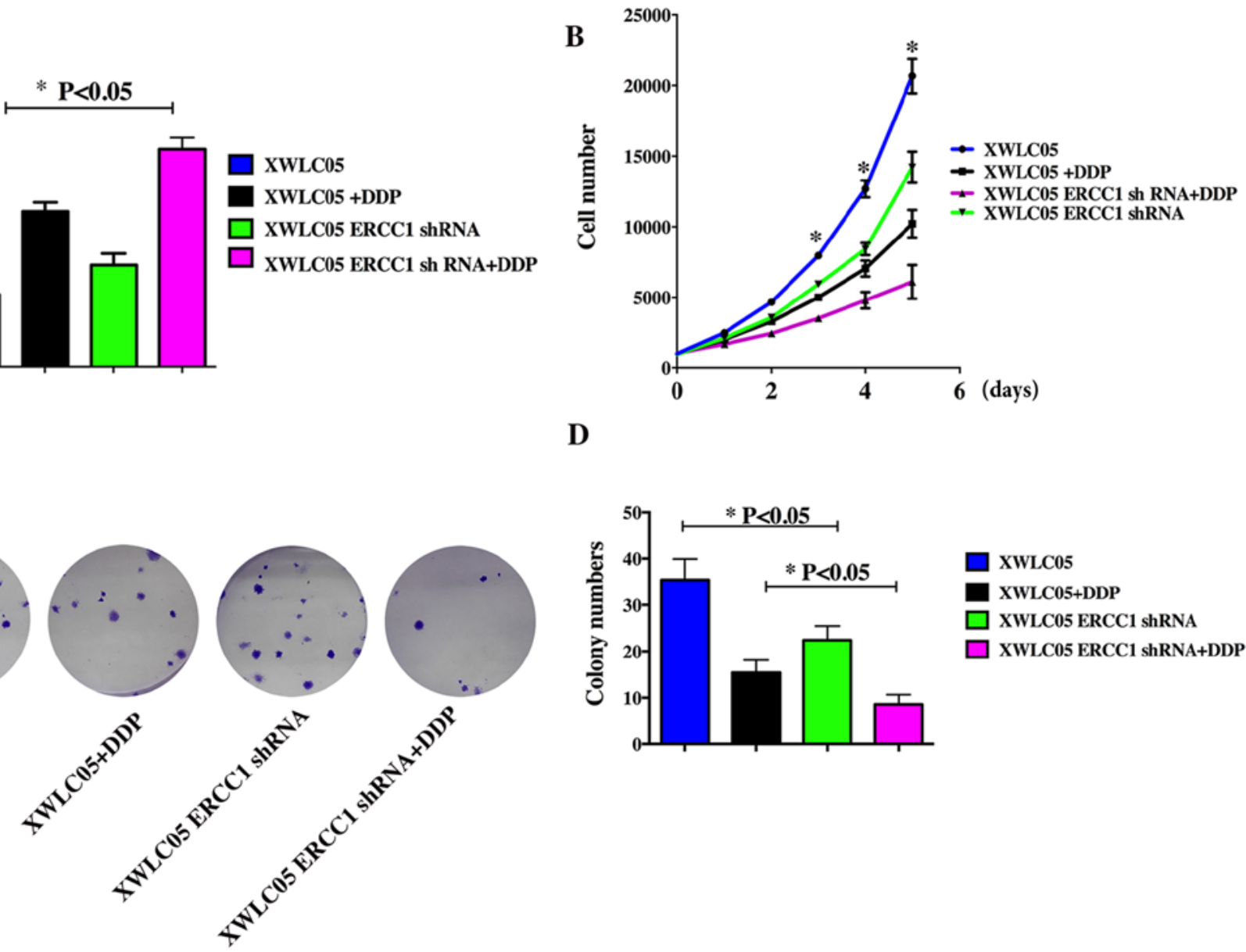

D
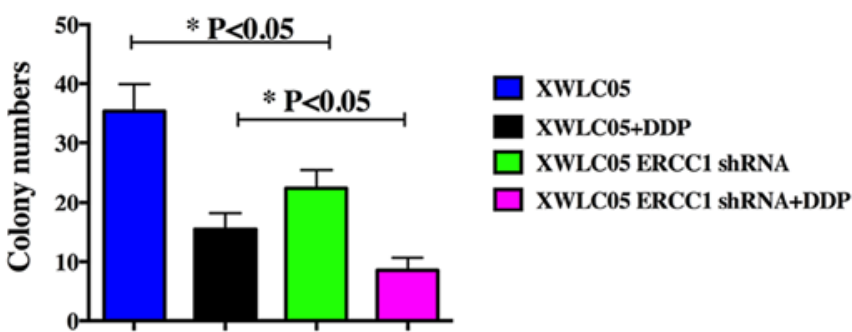

Figure 2. ERCC1 silencing increased cisplatin sensitivity of XWLC05 cell line in vitro. (A) Quantitative analysis of apoptotic cells under the treatment of cisplatin $(1 \mu \mathrm{M})$ in ERCC1 silencing cell line and its controls $(\mathrm{P}<0.05)$. Error bar $95 \%$ Confidence intervals $(\mathrm{Cis})$. (B) The proliferous capacity of $\mathrm{XWLC05}$ ERCC1-shRNA cell line and its control with or without the treatment of cisplatin $(1 \mu \mathrm{M})$ by CCK8 kit (P<0.05). Error bars $95 \%$ CIs. (C and D) Detection of colony formation ability of XWLC05 ERCC1-shRNA cell line and its control with or without the treatment of cisplatin (1 $\mu \mathrm{M})$ and quantitative analysis of colony formation $(\mathrm{P}<0.05)$. Error bars $95 \%$ CIs.

on the 7th edition of the AJCC Cancer Staging Manual and graded based on WHO criteria. The patients had undergone radical surgery at the Department of Thoracic Surgery of No. 3 Affiliated Hospital of Kunming Medical University (Yunnan Provincial Tumor Hospital) between January 2009 and September 2011. Each patient provided written informed consent, and the study was approved by the ethics committee of No. 3 Affiliated Hospital of Kunming Medical University (Yunnan Provincial Tumor Hospital). We explored the relationship between ERCC1 expression levels and patient survival by IHC staining of ERCCl in sections from the 106 patients, who had received cisplatin, carboplatin, gemcitabine, or vinorelbine as first-line chemotherapy between December 2008 and April 2012 in No. 3 Affiliated Hospital of Kunming Medical University (Yunnan Provincial Tumor Hospital). Complete follow-up information was available.

Statistical analysis. SPSS software (version 18.0) was used for statistical analysis. Student's t-test or ANOVA were used to compare quantitative data and Chi-square or Kruskal-Wallis tests were used to assess qualitative data. A P-value of $<0.05$ (two tailed) was considered statistically significant. The median progression-free survival (PFS) and overall survival (OS) were estimated by the Kaplan-Meier method and compared using a log-rank test.

\section{Results}

ERCC1 silencing reverses XWLCO5 cell cisplatin resistance. Expression of ERCC1 was examined in cultured unmanipulated XWLC05 cells and cells expressing empty vector (Vector Control) or ERCC1 shRNA (Fig. 1A and B). The level of ERCC1 in XWLC05-ERCC1-shRNA cells was significantly lower than that in XWLC05 and Vector Control cells.

To evaluate the anticancer effect of cisplatin, XWLC05, Vector Control, and XWLC05-ERCC1-shRNA cells were treated with concentrations of cisplatin ranging from $1 \times 10^{-4}$ to $1 \times 10^{4} \mu \mathrm{M}$. A dose-dependent cytotoxic effect of cisplatin was observed in these cell lines (Fig. 1C and D). The halfmaximal inhibitory concentration $\left(\mathrm{IC}_{50}\right)$ for XWLC05, Vector Control, and XWLC05-ERCC1-shRNA cells was 4.73, 4.54, and $1.31 \mu \mathrm{M}$, respectively $(\mathrm{P}<0.05)$.

ERCC1 silencing increases apoptosis and inhibits proliferation of cisplatin-treated cancer cells in vitro. We studied the effect of cisplatin treatment on apoptosis in the cell lines. 
A

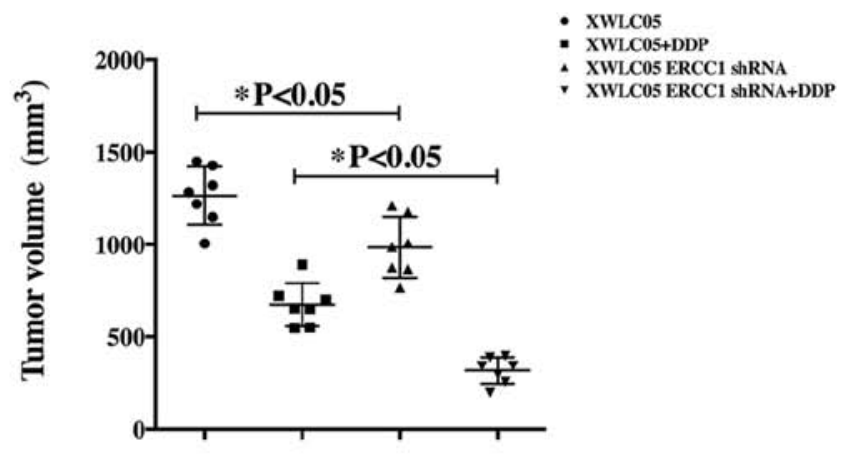

B

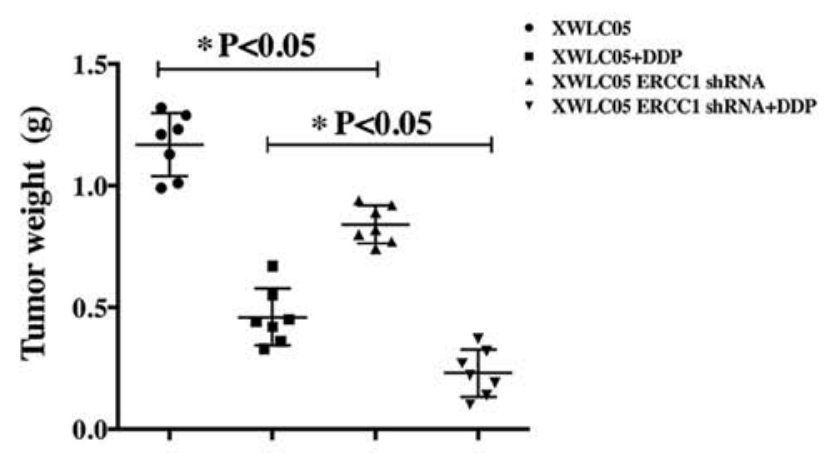

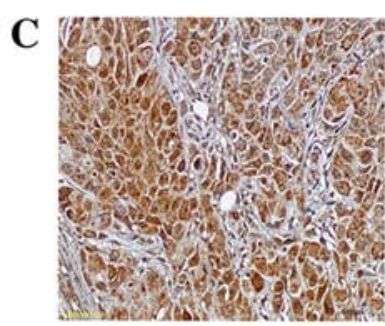

XWLC05

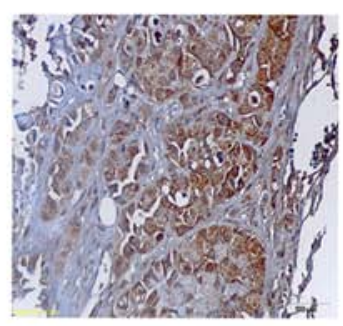

XWLC05+DDP

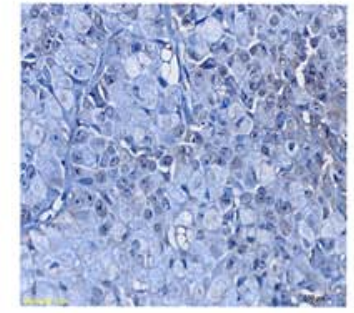

XWLC05 ERCC1

ShRNA

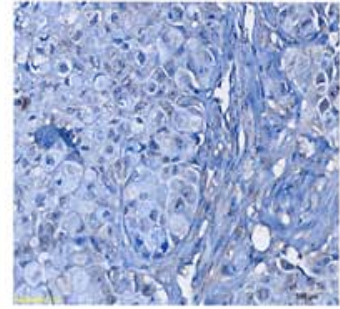

XWLC05 ERCC1

ShRNA+DDP

Figure 3. XWLC05 ERCC1-shRNA cell line and its control xenograft tumor burden in mice with or without the treatment of cisplatin. (A and B) In vivo tumorigenesis examined by animal assay and subcutaneous tumor growth from mice injected with XWLC05 ERCC1-shRNA cell line and its control with or without the treatment of cisplatin ( $\mathrm{n}=7$ for each group, $\mathrm{P}<0.05$ in XWLC05 ERCC1-shRNA groups). Error bars $95 \% \mathrm{CIs}$. Images show tumor volume and tumor weight of mice at the end of observation. (C) Immunohistochemical staining of xenograft tumor tissues. Tissues were stained with rabbit anti-ERCC1 antibody and visualized with goat anti-rabbit secondary antibody (magnification of $\mathrm{x} 400$ ).

Table I. Clinical characteristics of this cohort.

\begin{tabular}{ll}
\hline Characteristics & $\mathrm{N}(\%)$
\end{tabular}

Age at diagnosis (years)

Mean \pm SD

$62.7 \pm 11.3$

Gender

Male

Female

Smoking status

Yes

No

TNM stage

I

II

III

Pathology grading

Well-differentiated

Poor-differentiated

Receive chemotherapy

Yes

No

Receive radiotherapy

Yes

No
After $24 \mathrm{~h}$ treatment with cisplatin at $1 \mu \mathrm{M}, \mathrm{XWLC05}$, Vector Control, and XWLC05-ERCC1-shRNA cells were double-stained with Annexin V and PI and subjected to flow cytometry to quantify apoptosis (Fig. 2A). Cisplatin induced apoptosis in all cell lines; however, XWLC05-ERCC1-shRNA cells showed a higher apoptotic rate than Vector Control cells after incubation with or without cisplatin.

The CCK-8 assay showed that cell proliferation was significantly suppressed in XWLC05-ERCC1-shRNA cells compared with control cells treated with the same cisplatin concentration (Fig. 2B). Moreover, ERCC1 silencing also significantly inhibited the colony-forming ability of XWLC05 cells (Fig. 2C and D).

ERCC1 silencing inhibits proliferation and increases cisplatin sensitivity of XWLCO5 cells in vivo. The effect of ERCC1 on XWLC05 cells in vivo was investigated by injecting XWLC05ERCC1-shRNA cells and the corresponding Vector Control cells subcutaneously into nude mice and then treating the mice with vehicle or cisplatin $(5 \mathrm{mg} / \mathrm{kg})$ for 2 weeks. Tumor sizes were measured every 7 days. The mean volumes of tumors formed by XWL05 control cells and XWLC05-ERCC1shRNA cells at day 35 were 1264 and $984 \mathrm{~mm}^{3}$, respectively (Fig. 3A, $\mathrm{P}<0.05$ ). After cisplatin treatment, the mean tumor volumes at day 35 were 674 and $317 \mathrm{~mm}^{3}$, respectively (Fig. 3A, $\mathrm{P}<0.05)$. Thus, the growth of XWLC05-ERCC1-shRNA cells was most significantly inhibited by cisplatin in vivo. The tumor weights from the four mouse groups showed similar results (Fig. 3B). The mean weight of tumors formed by XWL05 control cells and XWLC05-ERCC1-shRNA cells at day 35 
$\mathbf{A}$

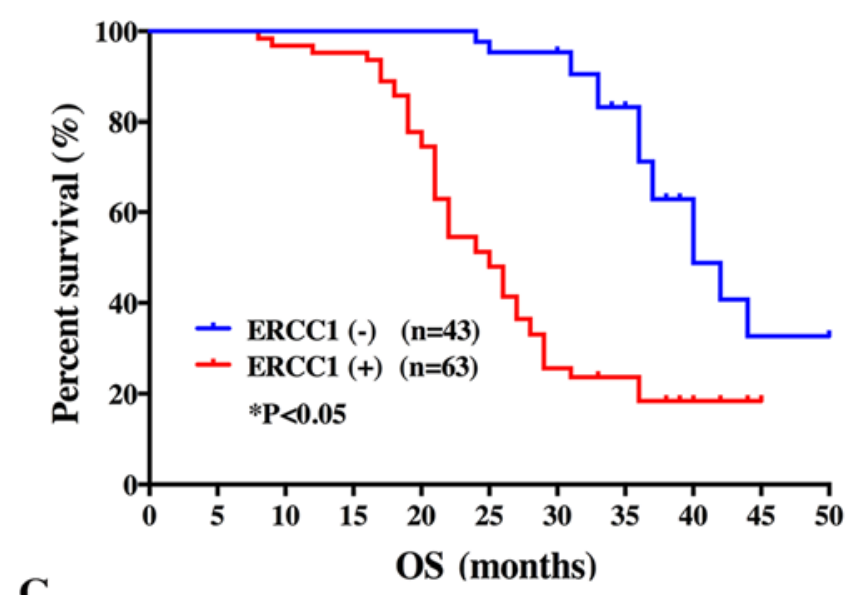

C

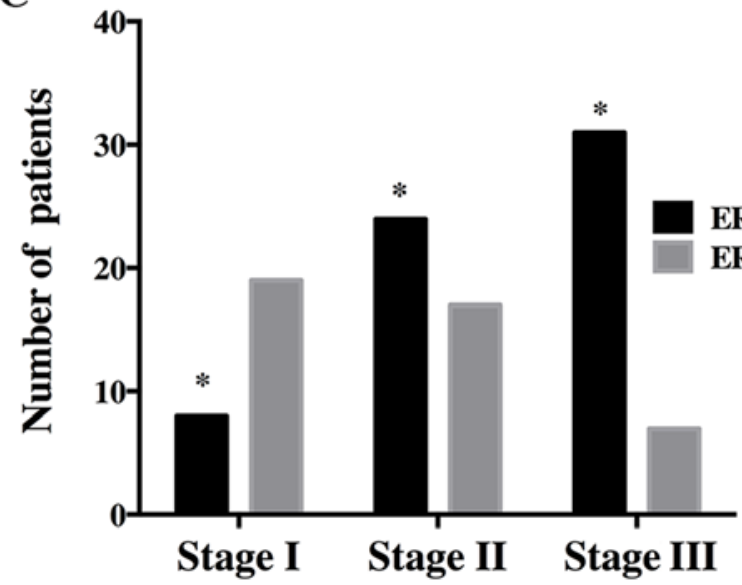

D

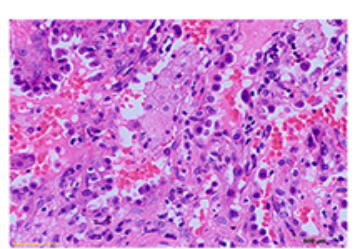

H\&E

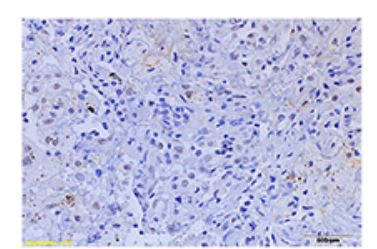

ERCC1(-)

B
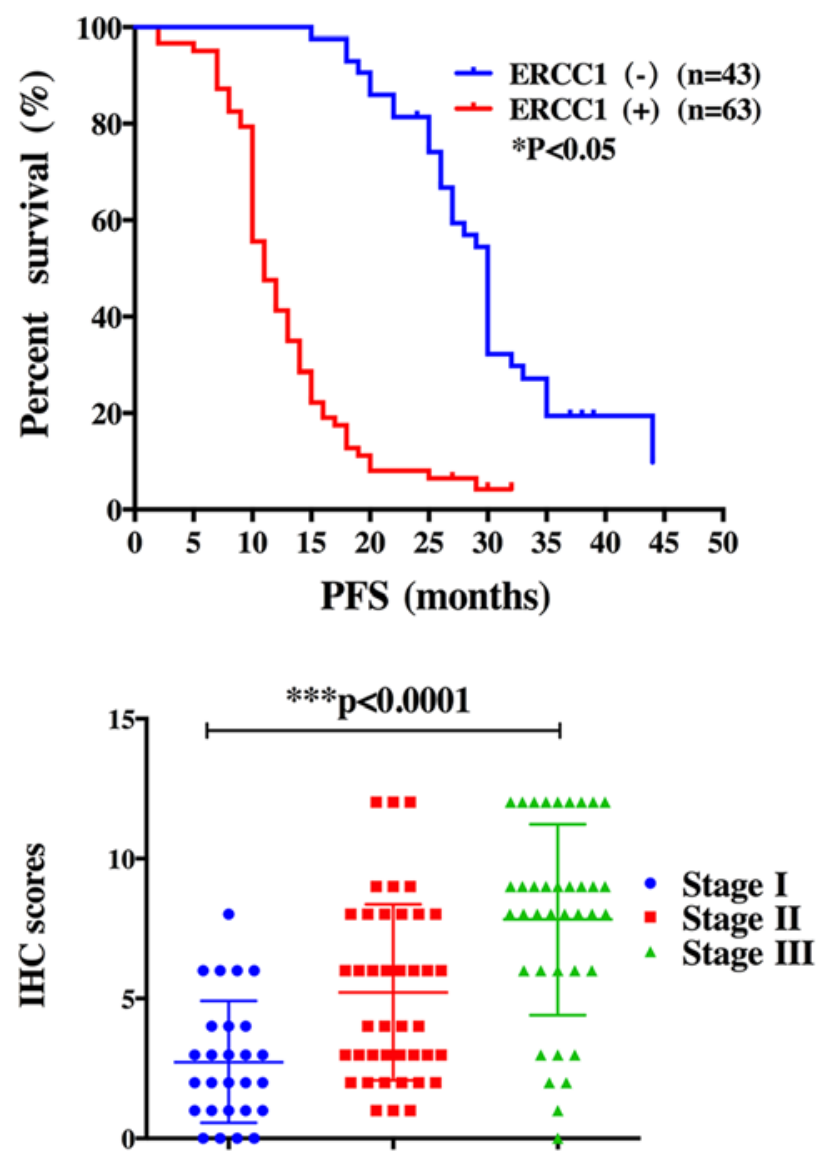

Stage I Stage II Stage III

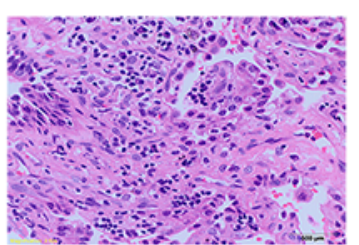

H\&E

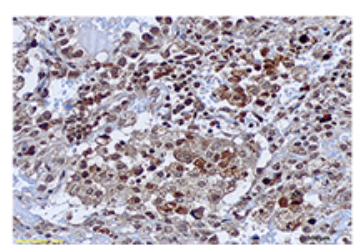

$\operatorname{ERCC1}(+)$

Figure 4. Correlation of ERCC1 expression in operable Xuanwei lung adenoma patient samples and the association of ERCC1 with patient survival. (A and B) Favorable overall survival and progression-free survival were associated with negative nuclear accumulation of ERCC1 ( $\mathrm{P}<0.05)$. (C) The number of ERCC1 positive patients and IHC score of each case in the different stage groups. Increasingly more patients were detected as ERCC1-positive as the disease progressed (Chi-square test was applied for the analysis of ERCC1 positive rate. P $<0.05$ ). Stage IIIa patients had the highest IHC score. (Kruskal-Wallis test was applied for the analysis of IHC score of protein expression "P<0.05). (D) Typical patient samples of ERCC1 expression. Slides were stained with rabbit anti-ERCC1 antibody and visualized with goat anti-rabbit secondary antibody (magnification of x400).

were $1.16 \mathrm{~g}$ and $0.84 \mathrm{~g}$, respectively $(\mathrm{P}<0.05)$. After cisplatin treatment, the mean tumor weight at day 35 were $0.46 \mathrm{~g}$ and $0.23 \mathrm{~g}$, respectively. We confirmed that expression of ERCC1 was efficiently inhibited in the xenograft mouse model by performing IHC analysis of tumor sections from each experimental group (Fig. 3C).

ERCCl expression predicts poor prognosis in lung adenoma patients. The mean age of the 106 patients in the study was 62.7 years (range $30-79$ years) (Table I). The surgical disease stage was $27(25.4 \%)$ stage I, $41(38.8 \%)$ stage II, and 38 (35.8\%) stage III. There were $31(29.2 \%)$ patients with welldifferentiated (low-grade) tumors and $75(70.8 \%)$ patients with poorly differentiated (high-grade) tumors. Among the
106 patients, 90 (84.9\%) received adjuvant chemotherapy and $40(37.7 \%)$ received radiotherapy. The mean follow-up interval was 30 months (range 2-55 months). At the last follow-up, 93 (87.7\%) patients had progressive disease after first-line chemotherapy and 64 (60.4\%) patients had died. The median PFS was 17 months (range, 2-44 months) and the median OS was 30 months (range, 8-50 months).

To confirm the relationship between the expression level of ERCC1 and the survival of lung adenoma patients, we performed IHC in the 106 patients with operable stage disease (Ia-IIIa). The results showed that positive ERCC1 staining was significantly associated with poor OS and PFS (Fig. 4A and B). In this patient cohort, we found that ERCC1 positivity correlated with disease progression. Lung adenoma samples were 
positive for ERCC1 in only 8 of 27 stage I patients but in 31 of 38 patients with stage III disease (Fig. 4C). This trend was also observed in the IHC score (Fig. 4D). For stage I patients, the IHC score was $2.74 \pm 0.42$, increasing significantly to $5.22 \pm 0.48$ in stage II patients and to $7.62 \pm 0.62$ in stage III patients. These data suggest that as the disease progresses, lung adenoma tissues become increasingly positive for ERCC1.

\section{Discussion}

In this study, we constructed a lentiviral vector encoding ERCC1-specific short hairpin RNA (shRNA) and transfected it into the lung adenocarcinoma cell line XWLC05, established from a patient from Xuanwei. Western blotting and quantitative PCR analysis confirmed the silencing efficiency of the ERCC1 shRNA construct. ERCC1 silencing increased XWL05 sensitivity to cisplatin, as reflected by the significant decrease in cisplatin $\mathrm{IC}_{50}$ values. Flow cytometric analysis showed that ERCC1 shRNA-infected cancer cells treated with cisplatin had a significantly higher rate of apoptosis compared with control cells. In vivo, the volume of tumors derived from XWLC05-ERCC1-shRNA cells was significantly lower after cisplatin treatment compared with tumors grown from control cells, which was consistent with the data from in vitro experiments. In a clinical cohort study of Xuanwei patients, we evaluated ERCC1 expression by IHC staining of tissue sections from 106 patients with operable lung adenoma. ERCC1 expression was predictive of worse prognosis, as reflected by the higher number of ERCC1-positive patients with advanced disease. This may be related to the active rate of cancer cell division in the advanced stage of disease, since DNA damage repair pathways are critical for cell division.

Drug resistance is associated with worse prognosis in cancer. Given the mechanism of platinum drug-induced killing of cancer cells and the involvement of ERCC1 in DNA damage repair, it is reasonable to assume that higher ERCC1 levels would be associated with worse prognosis. Our research confirms previous studies in this regard (27-32). Higher ERCC1 expression results in a lower mutational load in lung cancer patients (33) since ERCC1 repairs mismatch during DNA replication. Lower mutational load is related to the poor response to immunotherapy and body immunity of cancer patients, likely because it reduces the number of antigenic tumor epitopes available for detection by the immune system $(34,35)$. Our research confirms the ERCC1 expression status of Xuanwei lung adenoma patients and suggests that ERCC1 could be a predictive marker for identifying patients suitable for immunotherapy. Thus, positive ERCC1 expression may predict a poor response to immunotherapy. Further studies will be needed to establish the role of ERCC1 in the immune response of Xuanwei adenoma patients.

Previous studies $(36,37)$ suggested that lower ERCC1 RNA expression might be related to shorter survival of lung cancer patients and commercial ERCC1 IHC test was not practical in the prospective evaluation of chemotherapy resistance of lung cancer patients, which contrasts with the results observed here. One explanation for this discrepancy is that many factors are involved in platinum resistance. In addition to ERCC1, many other genes, such as YAP (38) and NEAT1 (39), play important roles in the complicated biological events underlying the resistance process. ERCC1 expression level and function can be affected by post-transcriptional modifications.

Many other aspects of treatment, including the platinum dose, subsequent radiotherapy, and combination therapy with agents such as tyrosine kinase inhibitors (TKI) for patients with mutated epidermal growth factor receptor (EGFR), may also be related to the OS and PFS of lung cancer patients. As for ERCC1 IHC commercial tests, it could be a much more complicated problem. Different antibody with different clone number from different company may lead to confused conclusion of lung cancer patients with ERCC1 expression, so more studies are urgently needed. There is an urgent need for a more appropriate antibody, better and more mature detecting methods instead of totally declining the possibility to predict chemotherapy response of lung cancer patients. We should emphasize that the clone number of antibody we used in our research was the same as that in IALT Bio study (27) (mouse, $8 \mathrm{~F} 1)$.

In this study, negative ERCC1 expression did benefit lung cancer patients who were administered with cisplatin based chemotherapy. Thus, we can make some deduction: positive ERCC1 expression may be a negative factor for lung cancer patients who were administered with cisplatin based chemotherapy. In addition, accumulating evidence indicates ERCC1 is a good marker for cellular or clinical resistance to cisplatin, carboplatin, and oxaliplatin $(7,40,41)$. ERCC1 is still a good predictive marker for chemotherapy.

Our study enrolled 106 patients from Xuanwei with operable cancer. These patients were positive for ERCC1 before administration of platinum-based chemotherapy, and the proportion of ERCC1-positive patients increased as the disease progressed. ERCC1 expression has been shown to predict the response to platinum-based therapy in advanced NSCLC patients (42). These observations serve as reminders of the significance of surgery in managing Xuanwei lung adenoma patients. Radical resection of lesions can reduce the ERCC1-positive tumor load in these patients, which is important for post-operative adjuvant therapy. Xuanwei lung adenoma patients diagnosed at an early disease stage may benefit from relatively complete resection of ERCC1-positive tumor tissue, thus ensuring a better response to adjuvant platinum-based chemotherapy.

There are some limitations to our study. All of the samples analyzed here were from Xuanwei lung adenoma patients. Most patients in this cohort did not undergo gene analysis for detection of EGFR mutant status and did not accept TKI treatment for economic reasons. The potential effects of these clinical factors on our study are unknown. In addition, patients with advanced lung adenoma (stage IIIb-IV) were not included in this study. We should also pay attention to the in vitro experiment because only one cell line was applied. In animal experiments, XWLC05-ERCC1-shRNA cells and control cells were injected subcutaneously, and the microenvironment in this location is quite different from that in human lung.

This study is the first to investigate ERCC1 expression in residents of Western China, which has a high incidence of lung adenoma. We examined ERCC1 gene-modified XWLC05 cells, originating from a Xuanwei lung adenoma patient, in vitro and in vivo. Our findings indicate that ERCC1 may play a critical role in the treatment of Xuanwei patients with 
platinum-based therapy and may have a significant effect on prognosis. Our research could thus be a good reference for further study of Xuanwei lung adenoma patients.

\section{Acknowledgements}

This study was supported by Yunnan Provincial Science and Technology Agency/Kunming Medical University Joint Project (2013FB164, 201501UH00557) to W.W.

\section{References}

1. Chen W, Zheng R, Baade PD, Zhang S, Zeng H, Bray F, Jemal A Yu XQ and He J: Cancer statistics in China, 2015. CA Cancer J Clin 66: 115-132, 2016.

2. Downward GS, Hu W, Large D, Veld H, Xu J, Reiss B, Wu G, Wei F, Chapman RS, Rothman N, et al: Heterogeneity in coal composition and implications for lung cancer risk in Xuanwei and Fuyuan counties, China. Environ Int 68: 94-104, 2014.

3. Liu ZY, He XZ and Chapman RS: Smoking and other risk factors for lung cancer in Xuanwei, China. Int J Epidemiol 20: 26-31, 1991.

4. Shen M, Chapman RS, He X, Liu LZ, Lai H, Chen W and Lan Q: Dietary factors, food contamination and lung cancer risk in Xuanwei, China. Lung Cancer 61: 275-282, 2008.

5. Lan Q, Chapman RS, Schreinemachers DM, Tian L and He X: Household stove improvement and risk of lung cancer in Xuanwei, China. J Natl Cancer Inst 94: 826-835, 2002.

6. Kim C, Chapman RS, Hu W, He X, Hosgood HD, Liu LZ, Lai H, Chen W, Silverman DT, Vermeulen R, et al: Smoky coal, tobacco smoking, and lung cancer risk in Xuanwei, China. Lung Cancer 84: 31-35, 2014.

7. Reed E: ERCC1 and clinical resistance to platinum-based therapy. Clin Cancer Res 11: 6100-6102, 2005.

8. Sodja E, Knez L, Kern I, Ovčariček T, Sadikov A and Cufer T: Impact of ERCC1 expression on treatment outcome in small-cell lung cancer patients treated with platinum-based chemotherapy. Eur J Cancer 48: 3378-3385, 2012.

9. Siddik ZH: Cisplatin: Mode of cytotoxic action and molecular basis of resistance. Oncogene 22: 7265-7279, 2003.

10. Martin LP, Hamilton TC and Schilder RJ: Platinum resistance: The role of DNA repair pathways. Clin Cancer Res 14: 1291-1295, 2008.

11. Zamble DB, Mu D, Reardon JT, Sancar A and Lippard SJ: Repair of cisplatin - DNA adducts by the mammalian excision nuclease. Biochemistry 35: 10004-10013, 1996.

12. Selby CP and Sancar A: Mechanisms of transcription-repair coupling and mutation frequency decline. Microbiol Rev 58: 317-329, 1994

13. Mu D, Hsu DS and Sancar A: Reaction mechanism of human DNA repair excision nuclease. J Biol Chem 271: 8285-8294, 1996.

14. Smith S, Su D, Rigault de la Longrais IA, Schwartz P, Puopolo M, Rutherford TJ, Mor G, Yu H and Katsaros D: ERCC1 genotype and phenotype in epithelial ovarian cancer identify patients likely to benefit from paclitaxel treatment in addition to platinum-based therapy. J Clin Oncol 25: 5172-5179, 2007.

15. Krivak TC, Darcy KM, Tian C, Armstrong D, Baysal BE, Gallion H, Ambrosone CB and DeLoia JA; Gynecologic Oncology Group Phase III Trial: Relationship between ERCC1 polymorphisms, disease progression, and survival in the Gynecologic Oncology Group Phase III Trial of intraperitoneal versus intravenous cisplatin and paclitaxel for stage III epithelial ovarian cancer. J Clin Oncol 26: 3598-3606, 2008.

16. Yamada Y, Boku N, Nishina T, Yamaguchi K, Denda T, Tsuji A, Hamamoto Y, Konishi K, Tsuji Y, Amagai K, et al: Impact of excision repair cross-complementing gene 1 (ERCC1) on the outcomes of patients with advanced gastric cancer: Correlative study in Japan Clinical Oncology Group Trial JCOG9912. Ann Oncol 24: 2560-2565, 2013.

17. Squires MH III, Fisher SB, Fisher KE, Patel SH, Kooby DA, El-Rayes BF, Staley CA III, Farris AB III and Maithel SK: Differential expression and prognostic value of ERCC1 and thymidylate synthase in resected gastric adenocarcinoma. Cancer 119: 3242-3250, 2013.
18. Kuhlmann JD, Wimberger P, Bankfalvi A, Keller T, Schöler S, Aktas B, Buderath P, Hauch S, Otterbach F, Kimmig R, et al: ERCC1-positive circulating tumor cells in the blood of ovarian cancer patients as a predictive biomarker for platinum resistance. Clin Chem 60: 1282-1289, 2014.

19. Hatch SB, Swift LP, Caporali S, Carter R, Hill EJ, MacGregor TP D'Atri S, Middleton MR, McHugh PJ and Sharma RA: XPF protein levels determine sensitivity of malignant melanoma cells to oxaliplatin chemotherapy: Suitability as a biomarker for patient selection. Int J Cancer 134: 1495-1503, 2014.

20. Bauman JE, Austin MC, Schmidt R, Kurland BF, Vaezi A, Hayes DN, Mendez E, Parvathaneni U, Chai X, Sampath S, et al: ERCC1 is a prognostic biomarker in locally advanced head and neck cancer: Results from a randomised, phase II trial. Br J Cancer 109: 2096-2105, 2013.

21. Cecere F, Bria E and Rosell R: DNA repair by ERCC1 in nonsmall-cell lung cancer. N Engl J Med 355: 2590-2591, author reply $2591,2006$.

22. Bepler G, Williams C, Schell MJ, Chen W, Zheng Z, Simon G, Gadgeel S, Zhao X, Schreiber F, Brahmer J, et al: Randomized international phase III trial of ERCC1 and RRM1 expressionbased chemotherapy versus gemcitabine/carboplatin in advanced non-small-cell lung cancer. J Clin Oncol 31: 2404-2412, 2013.

23. Soria JC: ERCC1-tailored chemotherapy in lung cancer: The first prospective randomized trial. J Clin Oncol 25: 2648-2649, 2007.

24. Shiraishi K, Kohno T, Tanai C, Goto Y, Kuchiba A, Yamamoto S, Tsuta K, Nokihara H, Yamamoto N, Sekine I, et al: Association of DNA repair gene polymorphisms with response to platinumbased doublet chemotherapy in patients with non-small-cell lung cancer. J Clin Oncol 28: 4945-4952, 2010.

25. Weiwei W, Zaoxiu H, Deguang W and Yong Z: Comparison of ERCC1 expression in lung adenoma tissue from Xuanwei of Yunnan province and other areas. Shangdong Med 22: 67-68, 2016.

26. Rubatt JM, Darcy KM, Tian C, Muggia F, Dhir R, Armstrong DK, Bookman MA, Niedernhofer LJ, Deloia J, Birrer M, et al: Pre-treatment tumor expression of ERCC1 in women with advanced stage epithelial ovarian cancer is not predictive of clinical outcomes: A Gynecologic Oncology Group study. Gynecol Oncol 125: 421-426, 2012.

27. Olaussen KA, Dunant A, Fouret P, Brambilla E, André F, Haddad V, Taranchon E, Filipits M, Pirker R, Popper HH, et al; IALT Bio Investigators: DNA repair by ERCC1 in non-small-cell lung cancer and cisplatin-based adjuvant chemotherapy. N Engl J Med 355: 983-991, 2006.

28. Wang X, Zhao J, Yang L, Mao L, An T, Bai H, Wang S, Liu X, Feng $\mathrm{G}$ and Wang J: Positive expression of ERCC1 predicts a poorer platinum-based treatment outcome in Chinese patients with advanced non-small-cell lung cancer. Med Oncol 27: 484-490, 2010

29. Ota S, Ishii G, Goto K, Kubota K, Kim YH, Kojika M, Murata Y, Yamazaki M, Nishiwaki Y,Eguchi K, et al: Immunohistochemical expression of BCRP and ERCC1 in biopsy specimen predicts survival in advanced non-small-cell lung cancer treated with cisplatin-based chemotherapy. Lung Cancer 64: 98-104, 2009.

30. Lee HW, Choi YW, Han JH, Kim JH, Jung JH, Jeong SH, Kang SY, Choi JH, Oh YT, Park KJ, et al: Expression of excision repair cross-complementation group 1 protein predicts poor outcome in advanced non-small cell lung cancer patients treated with platinum-based doublet chemotherapy. Lung Cancer 65: 377-382, 2009.

31. Holm B, Mellemgaard A, Skov T and Skov BG: Different impact of excision repair cross-complementation group 1 on survival in male and female patients with inoperable non-small-cell lung cancer treated with carboplatin and gemcitabine. J Clin Oncol 27: 4254-4259, 2009

32. Azuma K, Komohara Y, Sasada T, Terazaki Y, Ikeda J, Hoshino T, Itoh K, Yamada A and Aizawa H: Excision repair cross-complementation group 1 predicts progression-free and overall survival in non-small cell lung cancer patients treated with platinum-based chemotherapy. Cancer Sci 98: 1336-1343, 2007.

33. Yu D, Zhang X, Liu J, Yuan P, Tan W, Guo Y, Sun T, Zhao D, Yang M, Liu J, et al: Characterization of functional excision repair cross-complementation group 1 variants and their association with lung cancer risk and prognosis. Clin Cancer Res 14: 2878-2886, 2008.

34. Snyder A, Makarov V, Merghoub T, Yuan J, Zaretsky JM, Desrichard A, Walsh LA, Postow MA, Wong P, Ho TS, et al: Genetic basis for clinical response to CTLA-4 blockade in melanoma. N Engl J Med 371: 2189-2199, 2014. 
35. Rizvi NA, Hellmann MD, Snyder A, Kvistborg P, Makarov V, Havel JJ, Lee W, Yuan J, Wong P, Ho TS, et al: Cancer immunology. Mutational landscape determines sensitivity to PD-1 blockade in non-small cell lung cancer. Science 348: 124-128, 2015.

36. Simon GR, Sharma S, Cantor A, Smith P and Bepler G: ERCC1 expression is a predictor of survival in resected patients with non-small cell lung cancer. Chest 127: 978-983, 2005.

37. Schneider JG, Farhadfar N, Sivapiragasam A, Geller M, Islam S and Selbs E: Commercial laboratory testing of excision repair cross-complementation group 1 expression in non-small cell lung cancer. Oncologist 19: 459-465, 2014.

38. Cheng H, Zhang Z, Rodriguez-Barrueco R, Borczuk A, Liu H, Yu J, Silva JM, Cheng SK, Perez-Soler R and Halmos B: Functional genomics screen identifies YAP1 as a key determinant to enhance treatment sensitivity in lung cancer cells. Oncotarget 7: 28976-28988, 2016.
39. Jiang $P, W u ~ X$, Wang $X$, Huang $W$ and Feng Q: NEAT1 upregulates EGCG-induced CTR1 to enhance cisplatin sensitivity in lung cancer cells. Oncotarget 7: 43337-43351, 2016.

40. Reed E: Nucleotide excision repair and anti-cancer chemotherapy. Cytotechnology 27: 187-201, 1998.

41. Olaussen KA and Postel-Vinay S: Predictors of chemotherapy efficacy in non-small-cell lung cancer: A challenging landscape. Ann Oncol 27: 2004-2016, 2016.

42. Cobo M, Isla D, Massuti B, Montes A, Sanchez JM, Provencio M, Viñolas N, Paz-Ares L, Lopez-Vivanco G, Muñoz MA, et al: Customizing cisplatin based on quantitative excision repair cross-complementing $1 \mathrm{mRNA}$ expression: A phase III trial in non-small-cell lung cancer. J Clin Oncol 25: 2747-2754, 2007. 